\title{
COMPUTATIONAL BIM FOR GREEN RETROFITTING OF THE EXISTING BUILDING ENVELOPE
}

\author{
YAIK-WAH LIM ${ }^{1,2}$, TAKI EDDINE SEGHIER ${ }^{1}$, MUHAMAD FARHIN HARUN ${ }^{3}$, \\ MOHD HAMDAN AHMAD ${ }^{1}$, AZURAH A. SAMAH ${ }^{3}$ \& HAIRUDIN ABDUL MAJID ${ }^{3}$ \\ ${ }^{1}$ Faculty of Built Environment and Surveying, Universiti Teknologi Malaysia, Malaysia \\ ${ }^{2}$ Centre for the Study of Built Environment in the Malay World, Faculty of Built Environment and Surveying, \\ Universiti Teknologi Malaysia, Malaysia \\ ${ }^{3}$ School of Computing, Faculty of Engineering, Universiti Teknologi Malaysia, Malaysia
}

\begin{abstract}
Green retrofit is crucial to turning existing buildings into green buildings, but its design and analysis process is dependent on numerous disjointed methods. Various decisions are required to optimise the building efficiency, such as the choices of building materials, opening sizes, and glazing types. Therefore, this study explores the application of computational building information modelling (BIM) to automate the process of design decision-making for green retrofitting of the existing building envelope. A BIM tool (Revit), a visual programming tool (Dynamo) and multi-objective optimisation algorithm were integrated to create a computational BIM-based method for building envelope retrofitting by optimising overall thermal transfer value (OTTV) and construction investment cost. The proposed model was validated through a case study; the results showed that the optimised design achieved $44.78 \%$ reduction in OTTV with investment costs of RM (Malaysian ringgit) 369,182. The newly formulated computational BIM-based approach can improve the level of automation in green retrofitting design decision-making.
\end{abstract}

Keywords: automation, existing building, overall thermal transfer value, cost, efficiency.

\section{INTRODUCTION}

Existing buildings are often constrained by the old equipment, aging infrastructure and the lack of environmentally sensitive design, which causes poor sustainability performance and high energy consumption. Therefore, green retrofitting of existing buildings is vital to mitigate the negative environmental impacts caused by the building sector. Nevertheless, green retrofitting works are facing challenges such as high investment costs, loss of information, intensive labour, use of old technology, and low level of automation [1], [2]. In the green retrofitting design process, architects or designers normally vary multiple parameters at once in an unsystematic manner of decision-making (DM) with a low level of automation.

The development of building information modelling (BIM) allows complicated building modelling to be digitally constructed with precise geometry and accurate information. Data from BIM can be extracted and analysed to generate information for design DM. Especially, 4D BIM, 5D BIM and 6D BIM referring to time, cost and sustainability analyses can be employed to solve the challenges of green retrofit design. Therefore, the aim of this study is to develop an innovative approach by integrating BIM functionalities with the green retrofit DM process using computer programming to facilitate green retrofit measures for the existing building envelope.

\subsection{Green retrofitting of the building envelope}

Due to growing concerns regarding climate change, depletion of non-renewable resources and limitations on land use, great attention is being paid to retrofit existing buildings. As a result, some governments and international communities have made serious attempts in 
promoting energy performance in existing buildings [3]-[8]. Due to the limitation of existing building conditions, choosing the best possible measures is important to achieve efficient results and promising returns of investment.

Errors in information exchange among different parties is one of the challenges in a retrofitting project due to the large quantity of paper-based documents and drawings that are not well managed [9]. Thus, it is necessary to manage the information properly so that all parties in the retrofitting projects can receive accurate and relevant information. Besides, implementing green retrofitting faces time limitations, difficulties in convincing building owners to pay for investment, a lack of as-built documentations of buildings, outdated information and uncertainty of existing building conditions [8], [10].

In retrofitting projects, architects or designers need to vary multiple design parameters for DM on the retrofitting measures. The analyses for varied building performances, such as energy, thermal and visual, are usually disjointed and unsystematic, with a low level of automation, resulting in difficulties in investigating the impacts of individual design parameters [11]. An optimal combination of several strategies, which should be verified with different building energy simulations, is required to achieve retrofitting objectives for significant building performance improvement [3], [12]-[16]. Hence, the process of DM for selecting the best possible retrofit measure is a trade-off among several factors, such as energy, environmental, economic, technical, regulations, social, etc.

In existing building retrofitting, renovating the external building envelope is one of the most practical and efficient strategies because it can improve the building energy performance with minimal disturbance on the internal spaces and functions [17]. Heat gain and heat loss through the building envelope is one of the important aspects and it is usually controlled by specific standards and regulations. The choices of building envelope, opening sizes and glazing types are the contributing factors to achieve performance and costefficiency in retrofitting an existing building envelope.

One of the commonly used building envelope thermal assessment methods for airconditioned non-residential buildings is the overall thermal transfer value (OTTV) calculation. This calculation is one of the mandatory requirements under several green building certifications and standards of several countries, including Malaysia, Thailand, Singapore and Hong Kong. OTTV has been developed to guide project design teams to cut down on the external heat gain and hence reduce the cooling load of the air-conditioning system [18]. It is a mandatory requirement for both new and existing buildings. The complexity of the OTTV assessment resides in the process of collecting the necessary data to perform the required calculations.

In Malaysia, the OTTV calculation is based on the equation specified in the Malaysian Standards (MS) 1525:2014 [19]. From its equation and description, the OTTV calculation is derived from the following six design parameters: building orientation; correction factor of wall; window-to-wall ratio (WWR); shading devices; wall material and thickness; glass specification. The equation of OTTV for commercial buildings is given as follows:

$$
\text { OTTVi }+15 \alpha(1-W W R) U w+6(W W R) U f+(194 x \text { OF } x W W R x S C)
$$

where:

$W W R$ is the window-to-gross exterior wall area ratio for the orientation under consideration; $\alpha$ is the solar absorptivity of the opaque wall;

$U w$ is the thermal transmittance of the opaque wall $\left(\mathrm{W} / \mathrm{m}^{2} \mathrm{~K}\right)$;

$U f$ is the thermal transmittance of the fenestration system $\left(\mathrm{W} / \mathrm{m}^{2} \mathrm{~K}\right)$;

$O F$ is the solar orientation factor; and 
$S C$ is the shading coefficient of the fenestration system.

SHGC is solar heat gain coefficient where $\mathrm{SHGC}=S C \times 0.87$.

\subsection{Computational BIM for green building analysis}

BIM can characterise building geometry, spatial relationships, geographic information, quantities as well as properties of building elements, cost, materials, project schedule and other energy performance-related information, therefore, can be useful for solving green retrofitting DM and optimisation problems [20]-[25]. However, despite the increasing implementation of BIM in new building projects, the use of BIM in existing buildings' retrofitting is still limited [10], [26].

The integration of BIM-based rules and programming algorithms for data extraction and management, which is called computational BIM, helps the users to meet the design objectives. The application of computational BIM includes various aspects in the building industry, such as spatial, geometrical and structural design, and building energy performance analysis. Visual programming language (VPL) tools, such as Grasshopper and Dynamo, are used to perform the functions that include manipulating the geometric and metadata embedded in BIM. VPLs can automate repetitive tasks and make efficient the workflows of solving complex design problems.

Computational BIM can support sustainability analysis in the early stages of the building design process. Previous studies have adopted the computational BIM-based method to create workflows for building performance analysis [27]-[31]. VPL has been used to develop a framework for building passive performance optimisation [30], energy efficiency and daylighting [32], structural analysis [33], acoustical analysis [34] and building envelope performance assessment [31].

\subsection{Multi-objective optimisation}

The process of selecting the best possible solution during green retrofitting design DM faces the problem of conflicting objectives. This is because the optimal solution requires a tradeoff among several factors, namely energy, economy, technology, environment, regulations and social aspects [35]. Therefore, the use of computer algorithms for optimisation to support green retrofitting design DM can help to determine the optimal solution and increase the level of automation throughout the design process.

Previous research has integrated optimisation algorithms with the BIM-based process for building performances. Genetic algorithm (GA) and Pareto optimality were employed to solve a multicriteria optimal design problem of a BIM-based energy performance simulation model [36]. Search algorithms in combination with parametric models and dynamic energy simulation software were used to determine the optimal configurations of several building components including the building envelope [37]. In addition, some studies presented optimisation of the thermo-physical properties of the building envelope [38], [39] and the insulation thickness [40] of the opaque envelope.

There are many multi-objective optimisation (MOO) algorithms, which have different types of approach, and most of them require at least two conflicting objective functions to operate [41], [42]. This study employed an elitism MOO algorithm called non-dominated sorting genetic algorithm II (NSGA-II), which was developed by Deb et al. [43]. It is easy to apply and use the GA mechanism for the data manipulation, which is a perfect fit for combinatorial problems. 


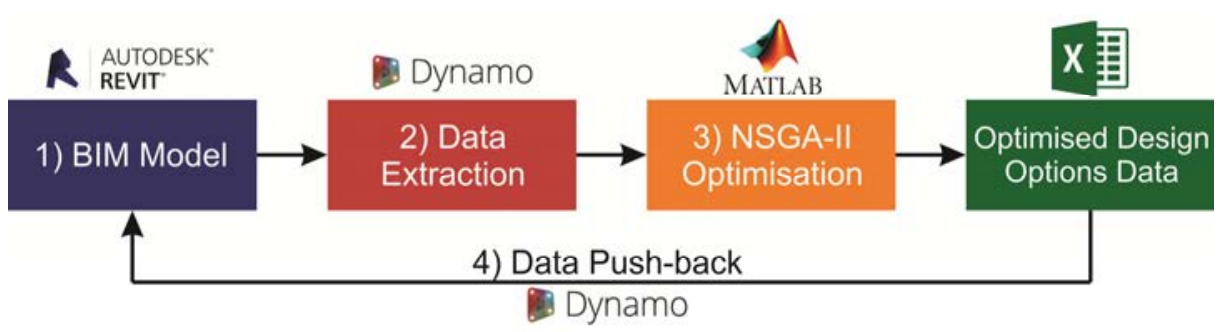

Figure 1: Conceptual framework of computational BIM-based method workflow.

\section{METHOD}

In this study, a conceptual framework (Fig. 1) of a computational BIM-based method for building envelope retrofitting was developed through four consecutive stages.

The first stage is the preparation of the BIM model for data extraction. The preparation process requires a BIM model of the existing building, which should conform to certain modelling rules and contain all the parameters required for building envelope performance assessment, such as thermal properties and construction cost. Second, Autodesk Revit (BIM authoring tool) and Dynamo (computational BIM tool) were selected for data extraction from the BIM model. This study employed Revit 2017.1 as the BIM authoring tool and Dynamo V.1.2.1 as the visual programming tool. Third, an NSGA II was selected and customised using MATLAB to perform the MOO of building envelope elements. Fourth, a Dynamo script was developed to push back the optimised data from MATLAB output to the BIM model to update the building envelope design automatically based on the optimum solution.

In this study, the OTTV and investment cost were selected as the building envelope green retrofitting design objectives for optimisation. This is because OTTV is one of the mandatory requirements under several green building certifications and standards to evaluate building envelope performances, whereas investment cost is a vital factor for choosing a promising green retrofit measure. The investment cost is defined as the construction cost of changing the original building envelope wall and window materials or quantity; if the optimised design remains as the original design, there will be no cost incurred.

The newly developed computation BIM-based method to optimise the OTTV and investment cost for green retrofitting of the building envelope was tested on an actual existing building and the generated optimisation results were compared to manual calculations for validation purposes.

\section{DEVELOPMENT OF COMPUTATIONAL BIM-BASED OPTIMISATION METHOD}

A workflow was established to optimise the OTTV of an existing building against the investment cost. As shown in Fig. 2, it performs a cycle of data starting by extracting the OTTV-related data from the BIM model using Dynamo. Then, this data is exported to MATLAB for MOO. Finally, the optimised data is pushed back again to update the BIM model automatically (i.e. window/wall type, window/wall area).

The components of the workflow include:

1. A BIM model (existing building) which contains the required data.

2. Two Dynamo scripts to extract the relevant data from the BIM model envelope (walls and windows). 


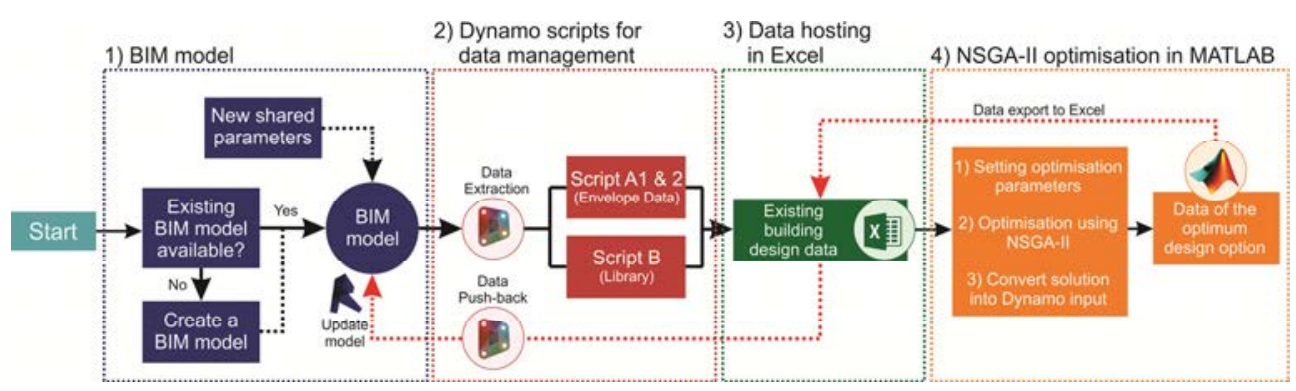

Figure 2: Logic workflow for OTTV and cost optimisation of existing building.

3. One Dynamo script to extract the library data of Revit (walls and windows), which will be used for optimisation process in MATLAB.

4. One multi-objective optimisation (MOO) algorithm (NSGA-II) was customised using MATLAB for OTTV and investment cost optimisation.

5. One Dynamo script to push-back the data of the optimum design option from MATLAB output to the model in Revit.

\subsection{Dynamo script for data management}

Four (4) Dynamo scripts, namely Script A1, A2, B and C, were developed to support the workflow of the computational BIM-based method for building envelope OTTV and investment cost optimisation. The scripts were used to extract data from the Revit model and library as well as to push back data to update the optimised model in Revit.

Script A1 and A2 were developed to extract data of the exterior opaque wall and window that are related to the OTTV requirement, including U-value, windows and walls area, window and wall orientation, shading coefficients (SC1, SC2), wall pitch angle, WWR (\%) and the solar orientation factor (OF).

Script B was intended to extract the library data of Revit wall and window elements for creating the new design alternatives during the optimisation process in MATLAB. The Revit library should contain different types of walls and windows of different sizes and a variety of thermal material properties to get accurate optimisation results. Apart from that, the cost parameter of each element in the library and the case study model should be assigned with its relevant value.

Script $\mathrm{C}$ was established to push-back the data of the optimum design option from MATLAB output to the Revit model to automatically update the model with the new solution, which consists of the best design alternative in terms of OTTV performance against investment cost.

\subsection{MATLAB programming for NSGA-II}

In this study, the optimisation problem is to find the best combination of wall and window material that produces optimum OTTV and investment cost. MATLAB 2017 was used as the environment for NSGA-II, where the objective functions and NSGA-II algorithm were modelled. The programming process involves customizing NSGA-II to suit the case study. During the development of NSGA-II, research constraint was also applied to ensure the output produced is accurate and feasible to use in the validation process. 
The optimisation framework for this study focuses on three phases. The first phase is the data set preprocessing where the related data set is pre-processed to ensure the optimisation performs better. The second phase is the optimisation phase where NSGA-II is applied to find the optimum combination of OTTV and investment. The final phase is to export this solution into Excel for post-processing analysis. The optimisation process is only focused on the numerical value for OTTV and investment cost.

The optimisation also needs to consider each material as the optimisation includes changing the WWR, and each window in the library has its own default area where not all windows can fit into the combination due to invalid wall and window area ratio. Any OTTV or cost generated from a flawed design cannot be used because when it is pushed back into the Revit model, it will produce an invalid wall area ratio.

For the NSGA-II optimisation, the population count was decided based on the data set count. A higher number of populations can lead to a higher rate of solution duplication in a single iteration, which will lead to a setback for the algorithm performance. As the calculation was complex and needs constant connection with the database, the computational time was quite long. Thus, 300 runs were tested by observing Pareto behaviour and during the 250th iteration onward the convergence is stopped, indicating that it is starting to over-fit.

\section{CASE STUDY}

A case study of an existing building was conducted to test and validate the newly proposed computation BIM-based method to optimise OTTV and investment cost for green retrofitting of the building envelope. The selected case study is an existing four-storey office building with a gross floor area of $7500 \mathrm{~m}^{2}$ (Fig. 3). This building is located in the Faculty of Built Environment and Surveying, Universiti Teknologi Malaysia, Johor Bahru, Malaysia with latitude of $1.56^{\circ} \mathrm{N}$ and longitude of $103.64^{\circ} \mathrm{E}$.

Every level of the building has air-conditioned spaces and naturally ventilated spaces. The building has four different façade orientations, which are facing north-west, north-east, south-east and south-west. Each façade consists of opaque brick walls with plaster finish and windows with single glazing. There was no existing BIM model available, thus the case study building was modelled in Revit based on 2D computer aided drawing (CAD). The building does not contain any external shading devices and most of the building elements were modelled with level of development (LOD) 300, including thermal properties that are required for OTTV calculation.

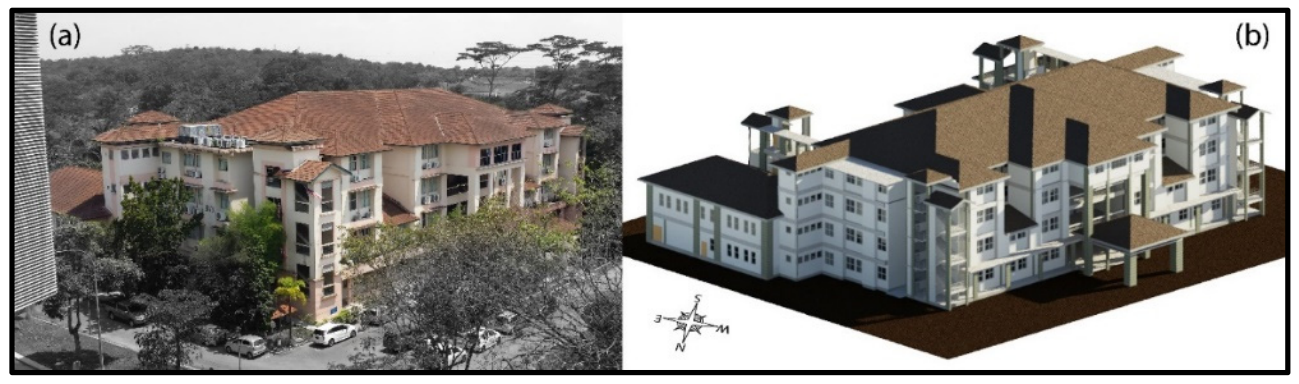

Figure 3: Case study of an existing building. (a) Photo; (b) BIM model. 
Table 1: Current OTTV and cost for the case study building.

\begin{tabular}{|l|c|c|}
\hline \multirow{2}{*}{ Orientation } & \multicolumn{2}{|c|}{ Current condition } \\
\cline { 2 - 3 } & OTTV $\left(\mathrm{W} / \mathrm{m}^{2}\right)$ & Material cost $(\mathrm{RM})$ \\
\hline North-east & 49.47 & 101,292 \\
\hline South-east & 64.26 & 114,189 \\
\hline North-west & 48.83 & 108,522 \\
\hline South-west & 63.17 & 111,478 \\
\hline Overall & 56.09 & 435,481 \\
\hline
\end{tabular}

\subsection{Evaluation and optimisation}

Evaluation for the case study building was carried out firstly by determining the original value of the OTTV and the cost for the original building envelope. Table 1 shows that the current OTTV was $56.09 \mathrm{~W} / \mathrm{m}^{2}$, which exceeded the requirement of $\leq 50 \mathrm{~W} / \mathrm{m}^{2}$ as stipulated in MS 1525:2014, therefore, optimisation was required. The construction cost of the current building façade envelope was RM435,481. By using NSGA-II, it was expected that an optimised solution, which has lower OTTV with reasonable retrofit cost, could be achieved.

The optimisation of the building was carried out based on each orientation. Hence, during the evaluation it was crucial that the OTTV of each orientation should not exceed $50 \mathrm{~W} / \mathrm{m}^{2}$, so that the overall OTTV would not exceed the requirement as stated in MS 1525:2014. The optimisation tests were conducted under two different conditions. The objective for multiple test condition (scenarios) was to determine a suitable setting that could be used with the current case study building. The proposed conditions of optimisation are listed as follows:

- Scenario 1: optimisation for window only; window area increment or decrement was limited to $20 \%$ variation.

- Scenario 2: optimisation for both wall and window; window area increment or decrement was limited to $20 \%$ variation.

The variation of window area was limited to $20 \%$ only in order to avoid any significant change of window sizes that may cause a design error or clashes with building structure components, such as beams and columns.

\subsection{Comparison of optimised and existing designs}

The optimisation results demonstrated that MOO could produce a lower OTTV than the original design. From each experiment, it can be concluded that the investment cost was acceptable because total material retrofit cost did not exceed the total building cost. The percentage of increment and decrement for each scenario is shown in Table 2.

In Scenario 1, when the optimisation was limited for windows only, the investment cost was the lowest, although the OTTV was not significantly reduced $(27.54 \%)$ due to the changes only affecting the windows. The cost produced was low because the wall area was larger than the window area for each orientation. In fact, both OTTV and cost were majorly affected by the wall area and construction materials. Although the drawback of Scenario 1 was that the OTTV produced was higher than Scenario 2, if the retrofit cost has more priority than OTTV, the solution produced by Scenario 1 can be considered as a good solution. 


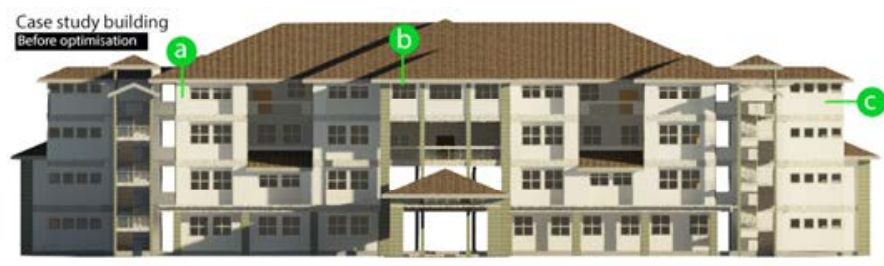

OTTV $=48.83 \mathrm{~W} / \mathrm{m}^{2} ;$ Material cost RM 108,522

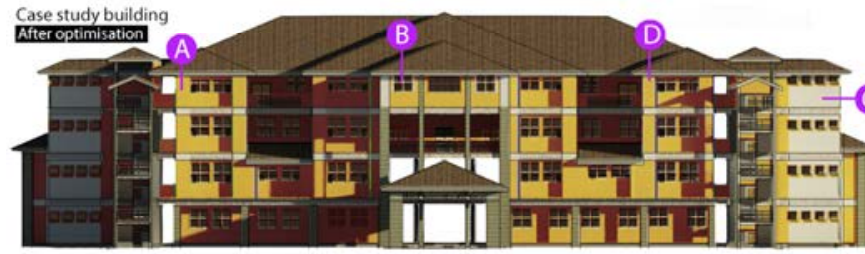

OTTV $=25.57 \mathrm{~W} / \mathrm{m}^{2} ;$ Investment cost RM 96,134
Before optimisation:

(a): all wall types $12 \mathrm{~cm}$ single brick with $15^{*} 2 \mathrm{~mm}$ plaster

(b): all windows with single glazing (U-value $=6.7 \mathrm{w} / \mathrm{m}^{2} . \mathrm{k}$ )

(c): walls that enclose naturally ventilated spaces (i.e. WC) have been excluded before running script Al

After optimisation:

(A): all walls: $12 * 2 \mathrm{~cm}$ double brick. $10 \mathrm{~cm}$ air cavity with $15^{*} 2 \mathrm{~mm}$ plaster (B): most of the windows with double glazing (U-value $=3.12$ $\left.w / m^{2} \cdot k\right)$

(C): the excluded walls remained with their initial color

(D): All envelop walls included in the optimization are assigned with a new color (for visualization purpose)

Figure 4: Original and optimised design of north-west façade (Scenario 2).

Table 2: OTTV reduction and investment cost for all tests.

\begin{tabular}{|l|c|c|c|c|c|c|}
\hline \multirow{2}{*}{ Orientation } & \multicolumn{3}{|c|}{ Scenario 1 } & \multicolumn{3}{c|}{ Scenario 2 } \\
\cline { 2 - 7 } & $\begin{array}{c}\text { OTTV } \\
\left(\mathrm{W} / \mathrm{m}^{2}\right)\end{array}$ & $\begin{array}{c}\text { OTTV } \\
\text { reduction } \\
(\%)\end{array}$ & $\begin{array}{c}\text { Investment } \\
\text { cost (RM) }\end{array}$ & $\begin{array}{c}\text { OTTV } \\
\left(\mathrm{W} / \mathrm{m}^{2}\right)\end{array}$ & $\begin{array}{c}\text { OTTV } \\
\text { reduction } \\
(\%)\end{array}$ & $\begin{array}{c}\text { Investment } \\
\text { cost (RM) }\end{array}$ \\
\hline North-east & 39.62 & 19.91 & 31,374 & 25.96 & 47.53 & 92,832 \\
\hline South-east & 42.50 & 33.87 & 57,571 & 41.65 & 35.19 & 83,553 \\
\hline North-west & 39.23 & 19.65 & 36,874 & 25.57 & 47.64 & 96,134 \\
\hline South-west & 41.40 & 34.46 & 62,845 & 31.38 & 50.32 & 96,663 \\
\hline Overall & 40.64 & 27.54 & 188,664 & 30.97 & 44.78 & 369,182 \\
\hline
\end{tabular}

Scenario 2 was a more open test where it involved changes of both wall and window, thus it was expected to produce a wider range of optimised OTTV than Scenario 1. As presented in Table 2, the OTTV produced by Scenario 2 was lower than both the existing condition and Scenario 1 . Scenario 2 OTTV is $44.78 \%$ lower than the original OTTV, which was almost twice reduction than Scenario 1.

As for the cost, Scenario 2 required a higher investment cost than Scenario 1. Scenario 1 consumed RM 188,664, while Scenario 2 needed RM 369,182, which was almost two times more than Scenario 1. The cost was increased due to the changes of wall materials in order to achieve lower U-value than the existing condition.

From Scenario 2, it can be concluded that the wider the range for material selection, the wider also the OTTV range, which can be lower than Scenario 1. When Scenario 1 was limited to only changing the windows, almost all windows were changed. This has proved that NSGA-II managed to control the trade-off by changing either the wall or window section rather than changing both materials.

In this study, the most optimal solution can be achieved when both walls and windows were optimised, with the window having no more than $20 \%$ of area changes using the available Revit library. However, depending on the priority of the green retrofitting, Scenario 
Table 3: Manual validation for the original design.

\begin{tabular}{|l|c|c|c|c|}
\hline \multirow{2}{*}{ Orientation } & \multicolumn{2}{|c|}{ OTTV $\left(\mathrm{W} / \mathrm{m}^{2}\right)$} & \multicolumn{2}{c|}{ Cost $(\mathrm{RM})$} \\
\cline { 2 - 5 } & $\begin{array}{c}\text { MATLAB } \\
\text { output }\end{array}$ & $\begin{array}{c}\text { Manual } \\
\text { calculation }\end{array}$ & $\begin{array}{c}\text { MATLAB } \\
\text { output }\end{array}$ & $\begin{array}{c}\text { Manual } \\
\text { calculation }\end{array}$ \\
\hline North-east & 49.47 & 49.47 & 101,292 & $101,291.95$ \\
\hline South-east & 64.26 & 64.26 & 114,189 & $114,188.65$ \\
\hline North-west & 48.83 & 48.83 & 108,522 & $108,521.88$ \\
\hline South-west & 63.17 & 63.17 & 111,478 & $111,478.25$ \\
\hline Overall & 56.09 & 56.09 & 435,481 & $435,480.75$ \\
\hline
\end{tabular}

Table 4: Manual validation for the optimised design.

\begin{tabular}{|l|c|c|c|c|}
\hline \multirow{2}{*}{ Orientation } & \multicolumn{2}{|c|}{ OTTV $\left(\mathrm{W} / \mathrm{m}^{2}\right)$} & \multicolumn{2}{c|}{ Cost (RM) } \\
\cline { 2 - 5 } & $\begin{array}{c}\text { MATLAB } \\
\text { output }\end{array}$ & $\begin{array}{c}\text { Manual } \\
\text { calculation }\end{array}$ & $\begin{array}{c}\text { MATLAB } \\
\text { output }\end{array}$ & $\begin{array}{c}\text { Manual } \\
\text { calculation }\end{array}$ \\
\hline North-east & 25.96 & 25.96 & 92,832 & $92,832.04$ \\
\hline South-east & 41.65 & 41.65 & 83,553 & $83,553.34$ \\
\hline North-west & 25.57 & 25.57 & 96,134 & $96,134.11$ \\
\hline South-west & 31.39 & 31.39 & 96,663 & $96,663.83$ \\
\hline Overall & 30.97 & 30.97 & 369,182 & $369,183.34$ \\
\hline
\end{tabular}

1 and Scenario 2 can both be considered as a good solution if the priority for the retrofit project was investment cost and OTTV, respectively. It is worth mentioning that the data push-back to the Revit model took around 3 minutes, nevertheless, the time may vary depending on the BIM model size and its design complexity.

\subsection{Validation}

The manual calculation was computed to validate the programmed OTTV and investment cost. The validation compared the MATLAB outputs with manual calculations. Table 3 presents the comparison between the two methods of calculation for the original design, while Table 4 tabulates the calculations for the selected optimised design (Scenario 2). Overall, the OTTV was calculated by using the Overall OTTV equation and overall cost is the total investment cost for all orientations. The comparisons show that the accuracy of the MATLAB output for both OTTV and cost is high.

\section{DISCUSSION AND CONCLUSION}

Green retrofitting the building envelope requires the design team to analyse the performances of various potential design options for design DM. Nevertheless, the process of evaluating the performance and altering the design is normally disjointed and time-consuming. Therefore, the findings of this study have provided a higher level of automation for green retrofitting design DM of the building envelope by using the newly developed computational BIM-based method. The integration of BIM (Revit), VPL (Dynamo) and MOO (NSGA-II in MATLAB) has opened up the possibility of automating and speeding up the process of green retrofitting performance evaluation and design DM with accurate, reliable and improved results.

The computational BIM-based method has been validated through a test case of the OTTV and investment cost optimisation of an existing office building as a case study. The results 
demonstrated that the method is able to give optimal solutions based on the priority of optimisation - for instance, Scenario 1 is better for minimal investment costs while still achieving the required $\leq 50 \mathrm{~W} / \mathrm{m}^{2}$, whereas Scenario 2 can provide the lower OTTV but with higher investment costs.

This research was carried out for the Malaysia context; the OTTV calculation and requirement were based on MS 1525:2014, which takes into consideration the tropical region near the Equator; the construction cost was based on Malaysia's construction industry. However, the proposed computational BIM-based method for green retrofitting the building envelope is applicable to other climatic and economic contexts by modifying the data inputs, calculation equations and objective functions. In addition, the method can also be further implemented for other objective functions apart from OTTV and cost in order to formulate a comprehensive integrated computational BIM-based optimisation tool for the green retrofitting of existing buildings.

\section{ACKNOWLEDGEMENT}

The authors would like to acknowledge the research funding by Ministry of Education, Malaysia (MOE) through Fundamental Research Grant Scheme (FRGS), project no. 5F103, titled "Computational Building Information Modelling-based Method for Green Retrofitting".

\section{REFERENCES}

[1] Chan, T.K. \& Theong, M.C., A review of the performance of the Malaysian construction industry. CIB World Congress, Brisbane, Australia, 5-9 May, 2013.

[2] Rashid, Y.R., Sulaiman, M.S., Aziz, A., Selamat, H., Yani, A.H.M.Y. \& Kandar, M.Z., Greening government's office buildings: PWD Malaysia experiences. Procedia Engineering, 21, pp. 1056-1060, 2011.

[3] Asadi, E., Silva, M.G.D., Antunes, C.H. \& Dias, L., A multi-objective optimization model for building retrofit strategies using TRNSYS simulations, GenOpt and MATLAB. Building and Environment, 56, pp. 370-378, 2012.

[4] Tobias, L. \& Vavaroutsos, G., Retrofitting Office Buildings to Be Green and EnergyEfficient: Optimizing Building Performance, Tenant Satisfaction, and Financial Return, Urban Land Institute, p. 308, 2010.

[5] Santamouris, M. \& Dascalaki, E., Passive retrofitting of office buildings to improve their energy performance and indoor environment: The OFFICE project. Building and Environment, 37(6), pp. 575-578, 2002.

[6] Ardente, F., Beccali, M., Cellura, M. \& Mistretta, M., Energy and environmental benefits in public buildings as a result of retrofit actions. Renewable and Sustainable Energy Reviews, 15(1), pp. 460-470, 2011.

[7] Durmus-Pedini, A. \& Ashuri, B., An overview of the benefits and risk factors of going green in existing buildings. International Journal of Facility Management, 1(1), pp. $1-15,2010$.

[8] Ma, Z., Cooper, P., Daly, D. \& Ledo, L., Existing building retrofits: Methodology and state-of-the-art. Energy and Buildings, 55, pp. 889-902, 2012.

[9] Roberts, S., Altering existing buildings in the UK. Energy Policy, 36(12), pp. 44824486, 2008.

[10] Volk, R., Stengel, J. \& Schultmann, F., Building information modeling (BIM) for existing buildings: Literature review and future needs. Automation in Construction, 38, pp. 109-127, 2014. 
[11] Wang, W., Zmeureanu, R. \& Rivard, H., Applying multi-objective genetic algorithms in green building design optimization. Building and Environment, 40(11), pp. 1512$1525,2005$.

[12] Welle, B., Haymaker, J. \& Rogers, Z., ThermalOpt: A methodology for BIM-based passive thermal multidisciplinary design optimization. CIFE Technical Report, June, 2011.

[13] Welle, B., Rogers, Z. \& Fischer, M., BIM-centric daylight profiler for simulation (BDP4SIM): A methodology for automated product model decomposition and recomposition for climate-based daylighting simulation. Building and Environment, 58, pp. 114-134, 2012.

[14] Song, S., Yang, J. \& Kim, N., Development of a BIM-based structural framework optimization and simulation system for building construction. Computers in Industry, 63(9), pp. 895-912, 2012.

[15] Stevanović, S., Optimization of passive solar design strategies: A review. Renewable and Sustainable Energy Reviews, 25, pp. 177-196, 2013.

[16] Nielsen, A.N., Jensen, R.L., Larsen, T.S. \& Nissen, S.B., Early stage decision support for sustainable building renovation: A review. Building and Environment, 103, pp. 165-181, 2016.

[17] Lim, Y.W., Mohd Zin, K., Mohd Hamdan, A., Ossen, D.R. \& Aminatuzuhariah, M.A., Building façade design for daylighting quality in typical government office building. Building and Environment, 57, pp. 194-204, 2012.

[18] BCA, Code on envelope thermal performance for buildings, 2008. www.bca.gov.sg/PerformanceBased/others/RETV.pdf.

[19] Department of Standards Malaysia, Malaysian Standard 1525:2014: Energy Efficiency and Use of Renewable Energy for Non-Residential Buildings - Code of Practice (2nd revision), 2014.

[20] Azhar, S., Brown, J. \& Faroughi, R., BIM-based sustainability analysis: An evaluation of building performance analysis software, 2008.

[21] Nour, M., Hosny, O. \& Elhakeem, A., A BIM based approach for configuring buildings' outer envelope energy saving elements. Journal of Information Technology in Construction, 20, pp. 173-192, 2015.

[22] Chen, L. \& Pan, W., BIM-aided variable fuzzy multi-criteria decision making of lowcarbon building measures selection. Sustainable Cities and Society, 27, pp. 222-232, 2016.

[23] Khaddaj, M. \& Srour, I., Using BIM to retrofit existing buildings. Procedia Engineering, 145, pp. 1526-1533, 2016.

[24] Lim, Y.W., Building information modeling for indoor environmental performance analysis. American Journal of Environmental Sciences, 11(2), pp. 55-61, 2015.

[25] Lim, Y.W. et al., BIM and genetic algorithm optimization for sustainable building envelope design. International Journal of Sustainable Development and Planning, 13(1), pp. 151-159, 2018.

[26] Ham, Y. \& Golparvar-Fard, M., Mapping actual thermal properties to building elements in gbXML-based BIM for reliable building energy performance modeling. Automation in Construction, 49, pp. 214-224, 2014.

[27] Asl, M.R., Stoupine, A., Zarrinmehr, S. \& Yan, W., Optimo: A BIM-based multiobjective optimization tool utilizing visual programming for high. Performance. Proceedings of the 33rd International Conference on Education and Research in Computer Aided Architectural Design in Europe, pp. 1-10, 2015. 
[28] Kensek, K. \& Kahn, W., Integration of environmental sensors with BIM seven case studies, June, 2013.

[29] Kensek, K., Visual programming for building information modeling: Energy and shading analysis case studies. Journal of Green Building, 10(4), pp. 28-43, 2015.

[30] Konis, K., Gamas, A. \& Kensek, K., Passive performance and building form: An optimization framework for early-stage design support. Solar Energy, 125, pp. 161$179,2016$.

[31] Seghier, T.E., Lim, Y.W., Ahmad, M.H. \& Samuel, W.O., Building envelope thermal performance assessment using visual programming and BIM, based on ETTV requirement of Green Mark and GreenRE. International Journal of Built Environment and Sustainability, 4(3), pp. 227-235, 2017.

[32] Asl, M.R., Zarrinmehr, S., Bergin, M. \& Yan, W., BPOpt: A framework for BIMbased performance optimization. Energy and Buildings, 108, pp. 401-412, 2015.

[33] Makris, M., Gerber, D.J., Carlson, A. \& Noble, D., Informing design through parametric integrated structural simulation. eCAADe 2013: Computation and Performance: Proceedings of the 31st International Conference on Education and Research in Computer Aided Architectural Design in Europe, 1, pp. 69-77, 2013.

[34] Vannini, A., andreaarch $\mid$ Architecture and Computation. https://andreaarch.wordpress.com/. Accessed on: 17 Feb. 2017.

[35] Yu, W., Li, B., Jia, H., Zhang, M. \& Wang, D., Application of multi-objective genetic algorithm to optimize energy efficiency and thermal comfort in building design. Energy and Buildings, 88, pp. 135-143, 2015.

[36] Oh, S., Kim, Y., Park, C. \& Kim, I., Process-driven BIM-based optimal design using integration of EnergyPlus, genetic algorithm, and Pareto optimality. Proceedings of Building Simulation, pp. 14-16, 2011.

[37] Machairas, V., Tsangrassoulis, A. \& Axarli, K., Algorithms for optimization of building design: A review. Renewable and Sustainable Energy Reviews, 31, pp. 101$112,2014$.

[38] Gossard, D., Lartigue, B. \& Thellier, F., Multi-objective optimization of a building envelope for thermal performance using genetic algorithms and artificial neural network. Energy and Buildings, 67, pp. 253-260, 2013.

[39] Jiang, F., Wang, X. \& Zhang, Y., Analytical optimization of specific heat of building internal envelope. Energy Conversion and Management, 63, pp. 239-244, 2012.

[40] Daouas, N., A study on optimum insulation thickness in walls and energy savings in Tunisian buildings based on analytical calculation of cooling and heating transmission loads. Applied Energy, 88(1), pp. 156-164, 2011.

[41] Harun, M.F., Samah, A.A., Majid, H.A., Yusoff, Y. \& Lim, Y.-W., Optimization of green building design to achieve green building index (GBI) using genetic algorithm (GA). 6th ICT International Student Project Conference: Elevating Community Through ICT, ICT-ISPC, pp. 1-4, January, 2017.

[42] Vachhani, V.L., Dabhi, V.K. \& Prajapati, H.B., Survey of multi objective evolutionary algorithms. IEEE International Conference on Circuit, Power and Computing Technologies, ICCPCT, Mar., 2015.

[43] Deb, K., Pratap, A., Agarwal, S. \& Meyarivan, T., A fast and elitist multi-objective genetic algorithm: NGSA-II. IEEE Transactions on Evolutionary Computing, 6(2), pp. 182-197, 2002. 